\title{
Performance Characteristics of a Cluster of 5-kW Laboratory Hall Thrusters
}

\author{
Mitchell L. R. Walker* \\ Georgia Institute of Technology, Atlanta, Georgia 30332 \\ and \\ Alec D. Gallimore \\ University of Michigan, Ann Arbor, Michigan 48109 \\ DOI: $\underline{10.2514 / 1.19752}$
}

\begin{abstract}
Performance characteristics of a $2 \times 1$ cluster of 5-kW Hall effect thrusters are investigated. The cluster and each thruster are evaluated over the power range of $1.5-6 \mathrm{~kW}$ at three facility pumping speeds. Analysis of the monolithic thrust measurements shows that as facility backpressure increases, the discharge current and thrust increase. The percent difference between the measured cluster thrust and the sum of the thrust for each monolithic thruster for the $10.46 \mathrm{mg} / \mathrm{s}$ anode flow rate varies from 11 to $16 \%$ as the operating pressure increases from $7.1 \times 10^{-4} \mathrm{~Pa}-\mathrm{Xe}$ $\left(5.3 \times 10^{-6}\right.$ Torr-Xe) to $3.7 \times 10^{-3} \mathrm{~Pa}-X e\left(2.8 \times 10^{-5}\right.$ Torr-Xe). The percent difference in thrust for the $5.25 \mathrm{mg} / \mathrm{s}$ flow rate varies from 0 to $6 \%$ as the operating pressure increases from $4.7 \times 10^{-4} \mathrm{~Pa}-\mathrm{Xe}\left(3.5 \times 10^{-6} \mathrm{Torr}-\mathrm{Xe}\right)$ to $2.0 \times 10^{-3} \mathrm{~Pa}-\mathrm{Xe}\left(1.5 \times 10^{-5}\right.$ Torr-Xe $)$. Comparison of the cluster and the monolithic thruster performance characteristics for conditions of nearly equal operating pressure shows that for the $5.25 \mathrm{mg} / \mathrm{s}$ anode flow rate, the cluster thrust is equal to the addition of the two monolithic thrusters and the anode efficiency and specific impulse are approximately equal to those of the monolithic thruster. An improved backpressure correction technique based on incremental current change was demonstrated to predict thrust changes within $-4 \%$ to $+2 \%$, significantly better than a simple random flux calculation that uses the facility pressure and chamber wall temperature.
\end{abstract}

\section{Introduction}

$\mathbf{T}$ HE combination of high specific impulse, high thrust efficiency, and high thrust density makes the closed-drift Hall thruster (CDT) appealing for a number of Earth-orbit space missions. CDTs can satisfy many of the spacecraft propulsion needs of the United States Air Force, NASA, and industrial satellite producers for the next several decades. The USAF has recently identified the highpower 50-150 kW CDT propulsion system as the baseline approach for a variety of missions [1]. Next-generation communication satellites are becoming larger and the onboard power is increasing. Recent satellite designs suggest that electric propulsion (EP) systems will have to double or triple in power from the current $3-5 \mathrm{~kW}$ systems within the next decade to satisfy commercial spacecraft needs. These trends suggest that vacuum systems will have to be modified to handle the added propellant flow rates demanded by these higher-power thrusters. Many national EP test facilities, although physically large enough to test $50-\mathrm{kW}$ thrusters, possess pumping speeds that are at least an order of magnitude too low to ameliorate facility pressure effects for plume/contamination studies and life testing [2].

If the tank pressure is too high, the background gas can artificially modify the exhaust plume as well as alter the operation of the CDT itself $[2,3]$. Thruster operation may be influenced by entrainment and/or ingestion of the background chamber molecules. This effect artificially increases the propellant mass flow rate of the engine, resulting in performance and operation changes consistent with the

Received 14 September 2005; revision received 2 March 2006; accepted for publication 2 April 2006. Copyright () 2006 by Mitchell L. R. Walker. Published by the American Institute of Aeronautics and Astronautics, Inc., with permission. Copies of this paper may be made for personal or internal use, on condition that the copier pay the $\$ 10.00$ per-copy fee to the Copyright Clearance Center, Inc., 222 Rosewood Drive, Danvers, MA 01923; include the code $\$ 10.00$ in correspondence with the CCC.

*Assistant Professor, High-Power Electric Propulsion Laboratory, Department of Aerospace Engineering, 449 Guggenheim Building, 270 Ferst Drive. Member AIAA.

${ }^{\dagger}$ Professor, Plasmadynamics and Electric Propulsion Laboratory, Department of Aerospace Engineering, 3037 FXB Building, 1320 Beal Avenue. Associate Fellow AIAA. increased number of propellant particles. Furthermore, plume diagnostic experiments can be affected through a variety of processes. For example, a large partial pressure of background gas molecules can affect ion current density and energy distribution measurements by artificially increasing the local charge density through increased charge-exchange collisions [4].

Although the Jet Propulsion Laboratory, U. S. Air Force Research Laboratory (AFRL), NASA John H. Glenn Research Center, and a number of laboratories in Europe have recently upgraded their pumping systems in anticipation of higher-powered thrusters, most facilities are incapable of testing 150-plus-kW CDTs. Moreover, the number of facilities that are capable of testing very high-power electric propulsion systems is not expected to change in the foreseeable future. One way to address the significant test costs and feasibility issues of high-power EP systems is the use of a modular system.

In response to this issue, the USAF has embarked on the concept of thruster clustering to reach its high power goal, i.e., the use of smaller Hall thrusters in a propulsion array [5]. Clustering allows a single, smaller Hall thruster that can be analyzed with ground-based testing to be used in a higher-power propulsion array. Whereas a cluster will likely have a lower total efficiency and higher dry mass than a monolithic device of equal power, clustering provides propulsion system redundancy and the ability to vary the system power while allowing thrusters in use to operate at their peak efficiency. Thus, a cluster is more likely to provide higher performance over a wider range of power than a monolithic engine.

The work presented here is directed at the development of a Hall thruster cluster test facility [6-8] $]$. A $2 \times 1$ cluster of P5, 5-kW Hall thrusters has been constructed $[9,10]$. This cluster facilitates the investigation of high-power Hall thruster operation and provides insight into how facility effects influence monolithic and cluster characteristics. In this study, the performance of each P5 Hall thruster is measured over a voltage range of 300-600 V at mass flow rates of 5.25 and $10.46 \mathrm{mg} / \mathrm{s}$. The two thrusters are then operated simultaneously and the performance of the cluster is measured over the same thruster operating conditions. In addition, the effect of facility backpressure on Hall thruster performance is quantified 
Table 1 LVTF background pressure for the investigated flow rates and xenon pumping speeds.

\begin{tabular}{lccccc}
\hline \hline Thruster & Anode $(\mathrm{mg} / \mathrm{s})$ & Cathode $(\mathrm{mg} / \mathrm{s})$ & Pressure $($ Torr-Xe) & Pressure Pa-Xe & Nominal Xenon $(1 / \mathrm{s})$ \\
\hline Monolithic & 5.25 & 0.92 & $9.1 \mathrm{E}-06$ & $1.2 \mathrm{E}-03$ & 70,000 \\
Cluster & 5.25 & 0.92 & $1.5 \mathrm{E}-05$ & $2.0 \mathrm{E}-03$ & 70,000 \\
Monolithic & 10.46 & 0.92 & $1.4 \mathrm{E}-05$ & $1.9 \mathrm{E}-03$ & 70,000 \\
Cluster & 10.46 & 0.92 & $2.8 \mathrm{E}-05$ & $3.7 \mathrm{E}-03$ & 70,000 \\
Monolithic & 5.25 & 0.92 & $5.3 \mathrm{E}-06$ & $7.1 \mathrm{E}-04$ & 140,000 \\
Cluster & 5.25 & 0.92 & $8.6 \mathrm{E}-06$ & $1.1 \mathrm{E}-03$ & 140,000 \\
Monolithic & 10.46 & 0.92 & $8.1 \mathrm{E}-06$ & $1.1 \mathrm{E}-03$ & 140,000 \\
Cluster & 10.46 & 0.92 & $1.3 \mathrm{E}-05$ & $1.7 \mathrm{E}-03$ & 140,000 \\
Monolithic & 5.25 & 0.92 & $3.5 \mathrm{E}-06$ & $4.7 \mathrm{E}-04$ & 240,000 \\
Cluster & 5.25 & 0.92 & $5.4 \mathrm{E}-06$ & $7.2 \mathrm{E}-04$ & 240,000 \\
Monolithic & 10.46 & 0.92 & $5.3 \mathrm{E}-06$ & $7.1 \mathrm{E}-04$ & 240,000 \\
Cluster & 10.46 & 0.92 & $8.9 \mathrm{E}-06$ & $1.2 \mathrm{E}-03$ & 240,000 \\
\hline \hline
\end{tabular}

through variation of the Large Vacuum Test Facility (LVTF) pumping speed.

\section{Experimental Apparatus}

Vacuum Facility

All experiments are conducted in the LVTF, shown schematically in Fig. 1. The thrusters are mounted at thruster station 1. The LVTF pumping speed is varied by changing the number of cryopumps in operation $[11,12]$. Table 1 shows the LVTF operating pressure at the average anode flow rates investigated: 5.25 and $10.46 \mathrm{mg} / \mathrm{s}$, both with a $0.92 \mathrm{mg} / \mathrm{s}$ cathode flow. For these flow rates, at nominal xenon pumping speeds of $70 \mathrm{kl} / \mathrm{s}$ (2 pumps), $140 \mathrm{kl} / \mathrm{s}$ (4 pumps), and $240 \mathrm{kl} / \mathrm{s}$ (7 pumps), the LVTF operating pressures range from $4.6 \times 10^{-4} \mathrm{~Pa}-\mathrm{Xe} \quad\left(3.5 \times 10^{-6}\right.$ Torr-Xe $)$ to $3.8 \times 10^{-3} \mathrm{~Pa}-\mathrm{Xe}$ $\left(2.8 \times 10^{-5}\right.$ Torr-Xe $)$ on xenon. A previous study shows that the nude gauge reading is the best estimate of the true chamber pressure [13].

Chamber pressure is monitored by a nude ionization gauge, as indicated in Fig. 1. The gauge is a Varian model UHV-24 nude gauge

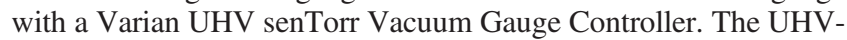
24 nude gauge is calibrated for air by the manufacturer. Pressure measurements are corrected for xenon using the known base pressure on air and a correction factor of 2.87 for xenon according to the following equation [14]:

$$
P_{c}=\frac{P_{i}-P_{b}}{2.87}+P_{b}
$$

where $P_{c}$ is the corrected pressure on xenon, $P_{b}$ is the base pressure, and $P_{i}$ is the indicated pressure when xenon is flowing into the vacuum chamber. The ionization gauge measures pressure over the

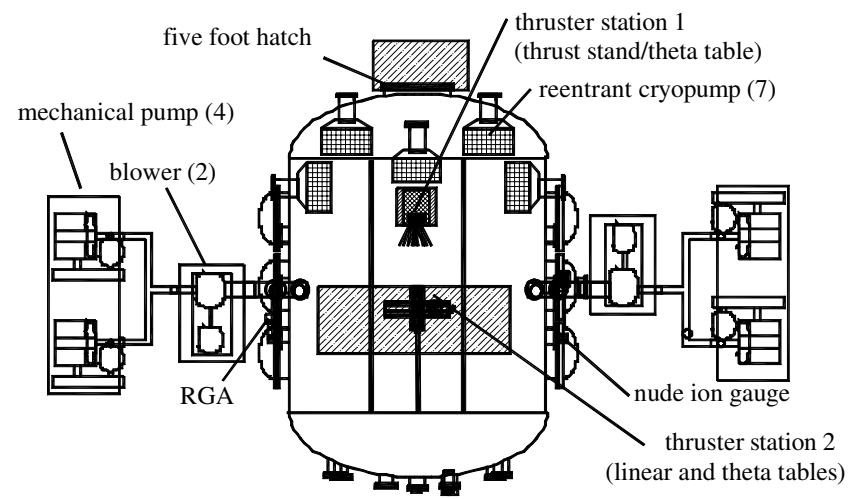

Fig. 1 Diagram of the LVTF ( $2 \times 1$ 5-kW P5 Hall thruster cluster.)

\footnotetext{
Data available on-line at http://www.varianinc.com/cgi-bin/nav?products/vacuum/measure/gauges\&cid=JPLHPIHFO [cited 15 April 2004].
}

range of $10^{-2} \mathrm{~Pa}\left(10^{-4}\right.$ Torr $)$ to $10^{-10} \mathrm{~Pa}\left(10^{-12}\right.$ Torr $)$ with an accuracy of $\pm 20 \%$ as reported by Varian.

\section{Hall Thruster}

All experiments are performed on the P5 $2 \times 1$ cluster of laboratory-model Hall thrusters [9]. The P5 has a mean diameter of $148 \mathrm{~mm}$, a channel width of $25 \mathrm{~mm}$, a channel depth of $38 \mathrm{~mm}$, and a nominal power rating of $5 \mathrm{~kW}$. Laboratory-model cathodes are located at the 12:00 position on each thruster. The cathode orifice is located approximately $30 \mathrm{~mm}$ downstream from the outer front pole piece. The cathode flow rate is set at $0.92 \mathrm{mg} / \mathrm{s}$ for all operating conditions. The original P5 discharge channel is machined from Mgrade boron nitride. The discharge chambers of the cluster elements use the less expensive HP-grade boron nitride. No appreciable change in the thruster operating characteristics or performance was observed due to the change in discharge channel material. A more detailed description of the P5 can be found in [9].

Each of the P5 Hall thrusters is powered by a separate set of power supplies and operates from its own cathode. The thruster electrical connections enter the chamber through two separate feedthrough ports. Each thruster discharge supply is connected to a filter consisting of a $1.3 \Omega$ resistor in series with the discharge current and a $95 \mu \mathrm{F}$ capacitor in parallel. The filter provides isolation of the discharge power supply from the discharge oscillations of the plasma and insures that any oscillations are not a product of feedback between the power supplies and plasma. Discharge current oscillations are measured with a F.W. Bell IHA-25 Hall-effect current sensor connected to a Tektronix TDS 3034B oscilloscope. High-purity (99.9995\% pure) xenon propellant is supplied to the Hall thrusters from compressed gas bottles through stainless-steel feed lines. MKS 1179JA mass flow controllers meter the anode and cathode propellant flows. The flow controllers are calibrated with a custom apparatus that measures gas pressure and temperature as a function of time in an evacuated chamber of known volume. The mass flow controllers have an accuracy of $\pm 1 \%$ full scale. Thus, the cathode and anode flow rates in Table 1 have an uncertainty of \pm 0.02 and $\pm 0.20 \mathrm{mg} / \mathrm{s}$, respectively.

\section{Thrust Stand}

Thrust is measured with a high-power null-type inverted pendulum type thrust stand [15]. The springs of the stand are made with extra stiffness to accommodate the weight of high-power thrusters. The null-type thrust stand holds the thruster at a set position at all thrust levels, which reduces error in the thrust by eliminating changes in the elevation of the thrust vector. The uncertainty of the thrust measurements in this experiment, determined by examination of the hysteresis and drift of the zero offset and calibration slope variation, is $\pm 1 \mathrm{mN}$.

In situ thruster/thrust-stand leveling is performed with a remotely controlled geared dc motor coupled to a jackscrew. A remotely controlled geared dc motor-driven pulley system is employed to provide in situ thrust-stand calibration by loading and off-loading small weights to simulate thrust before and after each test point. A linear curve-fit of null-coil voltage versus calibrated weight (thrust) 
is then obtained and used for performance measurements. Soon after the thruster is turned off, a post-test calibration is performed. Current is passed through each set of thruster magnetic coils, and magnetic tares are found to be negligible. Xenon is passed through both of the cathodes, and the cold flow tares are also found to be negligible. This last result is expected because the cathode centerlines are inclined approximately $45 \mathrm{deg}$ below the horizontal. Anode flow tares are not required because the anode flow is closed throughout the calibration.

To maintain thermal equilibrium within the thrust stand at highpower Hall thruster operating conditions, the stand is actively cooled with a VWR International 1172 refrigerated recirculating chiller. The thrust stand cooling consists of two and one-half parallel cooling circuits that travel through the structure and outer radiation shroud. The shroud cooling water temperature is monitored by the chiller and never increases by more than $5^{\circ} \mathrm{C}$ over the thruster-off condition.

\section{Cluster Spacing}

One of the most important criteria for Hall thruster clustering is the spacing of the array elements. To minimize structural mass and the physical envelope of the cluster, the elements of the cluster should be as close as possible without adversely affecting their performance. In large part, the magnetic field inside the Hall thruster channel governs the performance of the Hall thruster [16]. The cluster elements are spaced $40 \mathrm{~cm}$ apart (centerline-to-centerline) to ensure that the magnetic field within the discharge chamber and the external radial field are unaffected by the adjacent element of the cluster array at the maximum magnetic field strength operating condition. The maximum magnetic field operating condition has an inner coil current of $8.53 \mathrm{~A}$ and an outer coil current of $2.05 \mathrm{~A}$. The radial spacing of $40 \mathrm{~cm}$ is selected by measuring the radial magnetic field of one thruster and then of the cluster while increasing centerline spacing. The differences in the radial component of the magnetic field (internal and external) between these two configurations are found to be negligible with a centerline spacing of $40 \mathrm{~cm}$. The magnetic field is measured $6 \mathrm{~mm}$ upstream of the thruster exit plane with a standard Hall probe mounted on a linear motion table that provides an axial position accuracy of $\pm 1 \mathrm{~mm}$. The error in the magnetic field strength measurement is $\pm 5 \%$.

The electric fields within the plume plasma are also considered for thruster element spacing. The magnitude of the plasma potential in the plume is not large enough to create an electric field sufficient to cause a substantial deviation in the trajectory of high-speed ions created in the discharge channel. Therefore, plume interaction should not be large enough to affect the performance of the individual elements. However, weak electric fields in the plume may alter the fringes of plume by changing the trajectories of the slow CEX ions [7]. This effect is not investigated in this study.

\section{Experimental Results}

The primary goal of this study is to compare the performance of a single thruster element to the cluster array at three facility pumping speeds. First, the performance of each thruster is measured separately to ensure that the thrusters are nearly identical. Next, the performance of the cluster is measured with both engines operating at anode flow rates of 5.25 and $10.46 \mathrm{mg} / \mathrm{s}$ over a discharge voltage range of 300$600 \mathrm{~V}$. To investigate the effect of facility background pressure, the performance of the monolithic thrusters and cluster are measured over the range of pressure presented in Table 1 .

\section{Performance}

The effect of facility backpressure on Hall thruster performance is investigated by measuring the performance of the P5-A and P5-B at three pumping speeds. The anode mass flow rate and magnet settings remain constant at each power setting across the three pumping speeds. As the facility backpressure increases, the thruster discharge current and thrust increase as more background xenon gas is ingested into the thruster discharge chamber. All performance parameters presented exclude the cathode.

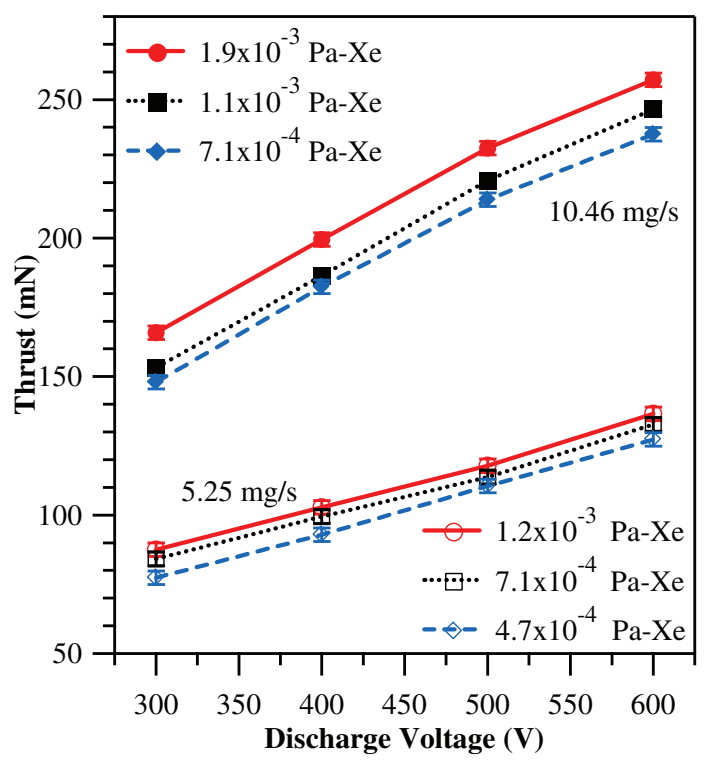

Fig. 2 The P5-A thrust measurements at anode flow rates of 5.25 and $10.46 \mathrm{mg} / \mathrm{s}$ as a function of discharge voltage at nominal pumping speeds of 70,140 , and $240 \mathrm{kl} / \mathrm{s}$.

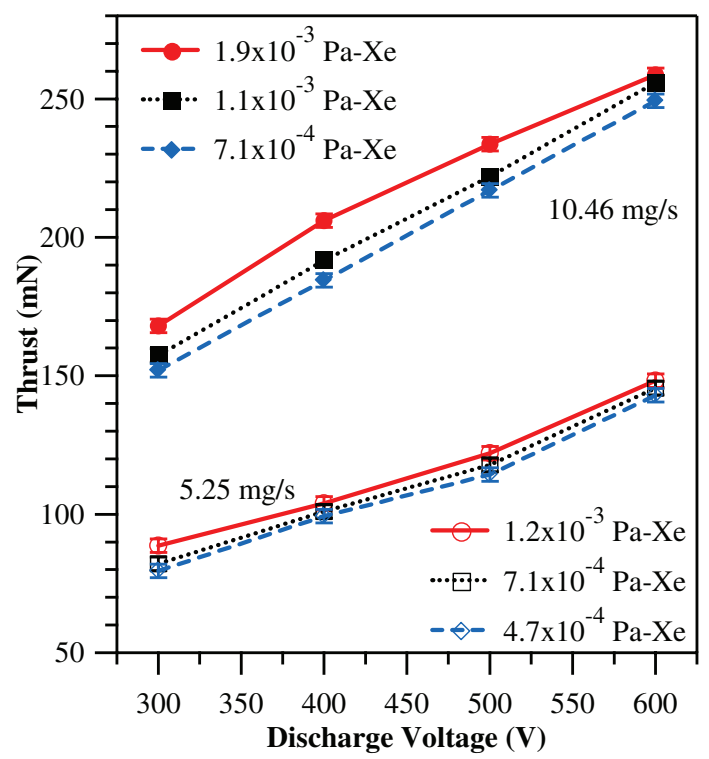

Fig. 3 The P5-B thrust measurements at anode flow rates of 5.25 and $10.46 \mathrm{mg} / \mathrm{s}$ as a function of discharge voltage at nominal pumping speeds of 70, 140, and $240 \mathrm{kl} / \mathrm{s}$.

Figures 2 and 3 present the measured thrust of the P5-A, $T_{\mathrm{P} 5-\mathrm{A}}$, and $\mathrm{P} 5-\mathrm{B}, T_{\mathrm{P} 5-\mathrm{B}}$, as a function of discharge voltage for anode flow rates of 5.25 and $10.46 \mathrm{mg} / \mathrm{s}$. The thrust produced by each of the monolithic thrusters is nearly identical within $5 \%$ and increases with increasing backpressure, as expected. The agreement gives confidence in the construction of the cluster elements. Figures $\underline{2}$ and $\underline{3}$ also show that the $T_{\mathrm{P} 5-\mathrm{A}}$ and $T_{\mathrm{P} 5-\mathrm{B}}$ are close to the thrust of the original P5 Hall thruster within the error of the thrust measurement, verifying that the thrusters are assembled similarly to the original P5 Hall thruster $[\underline{9}, 17]$.

The performance of the cluster is measured after the individual thrusters are characterized. Figure 4 shows that thrust of the cluster, $T_{C}$, increases as the facility backpressure increases, as was seen with the monolithic thruster. It is not possible to measure the performance of the cluster at the upper facility operating pressures and discharge voltages. As the facility backpressure increases, the discharge current and the amplitude of the discharge current oscillations increase as more background gas is ingested into the discharge 


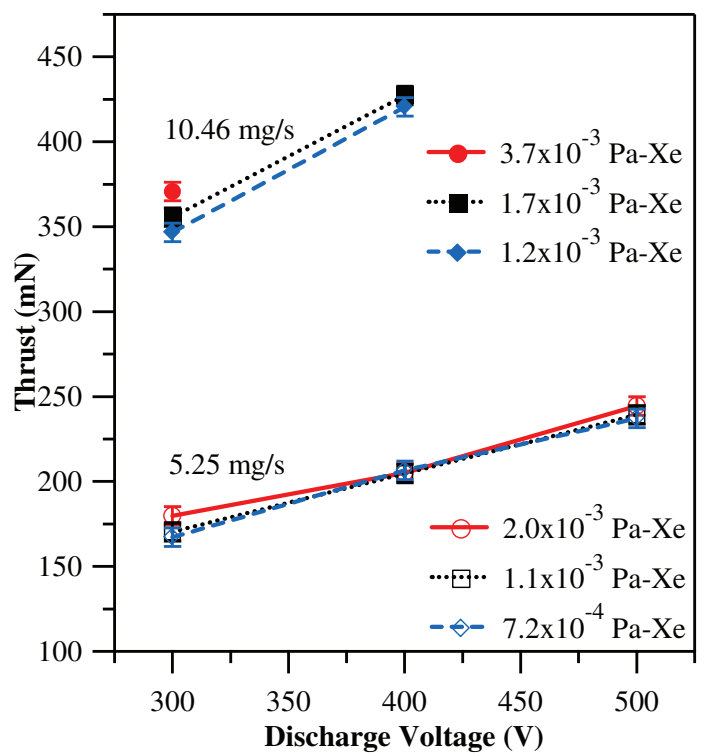

Fig. 4 Cluster thrust measurements at anode flow rates of 5.25 and $10.46 \mathrm{mg} / \mathrm{s}$ as a function of discharge voltage at nominal pumping speeds of 70, 140, and $240 \mathrm{kl} / \mathrm{s}$.

chamber. At the upper facility operating pressures, the instability in the discharge current becomes more severe as the discharge voltage is increased for constant backpressure. The amplitude of the discharge current oscillations increases to a maximum of $\pm 3 \mathrm{~A}$ as the backpressure increases. This trend continues until the oscillations disrupt the discharge. In addition, as the thruster approaches the discharge voltage disruption condition, portions of the inner channel begin to glow orange. It appears as though the ingested background gas and consequent discharge oscillations enhance the thermal conductivity to the boron nitride channel walls.

\section{Discharge Current}

The time-varying discharge current of each Hall thruster and of the cluster is measured at each operating condition with an oscilloscope with a $2.5 \mathrm{MHz}$ sample frequency. All discharge current measurements are made after the thrusters have operated for a minimum of $1 \mathrm{~h}$. Fast Fourier transforms of these discharge current signals show that the discharge is composed of oscillation frequencies of $0.85-10.4 \mathrm{kHz}$, which are characteristic of Hall thruster operation [17].

The measurements show that as the facility operating pressure increases, the amplitude of the current oscillations increases. The amplitude of the current oscillations of the P5-A operating at $300 \mathrm{~V}$, $4.92 \mathrm{~A}$ at an operating pressure of $4.6 \times 10^{-4} \mathrm{~Pa}\left(3.5 \times 10^{-6}\right.$ Torr $)$ is approximately $17 \%$ of the average discharge current. Figure 5 shows the discharge current of the cluster elements with the P5-A operating at $300 \mathrm{~V}, 5.14 \mathrm{~A}$ and the P5-B operating at $300 \mathrm{~V}, 4.96 \mathrm{~A}$ at an operating pressure of $7.2 \times 10^{-4} \mathrm{~Pa}\left(5.4 \times 10^{-6}\right.$ Torr $)$. The cluster operates well at this condition, but the amplitude of the discharge current oscillations of the P5-A increases to $22 \%$ of the average discharge current because of the increase in facility backpressure. The amplitude of the P5-B discharge oscillations is approximately $14 \%$ of the average discharge current. The difference between the P5-A and P5-B oscillation amplitudes may be caused by varying component material properties and assembly tolerances typical of hand-built thrusters, cathodes, and discharge filters.

The discharge current of the cluster with the P5-A operating at $300 \mathrm{~V}, 5.76 \mathrm{~A}$ and the P5-B operating at $300 \mathrm{~V}, 5.68 \mathrm{~A}$ at an operating pressure of $3.7 \times 10^{-3} \mathrm{~Pa}\left(2.8 \times 10^{-5}\right.$ Torr $)$ have increased from the values measured at the $7.2 \times 10^{-4} \mathrm{~Pa}$ operating pressure. Furthermore, the amplitudes of the discharge oscillations have increased to approximately $37 \%$ of the discharge current for both the $\mathrm{P} 5-\mathrm{A}$ and P5-B.

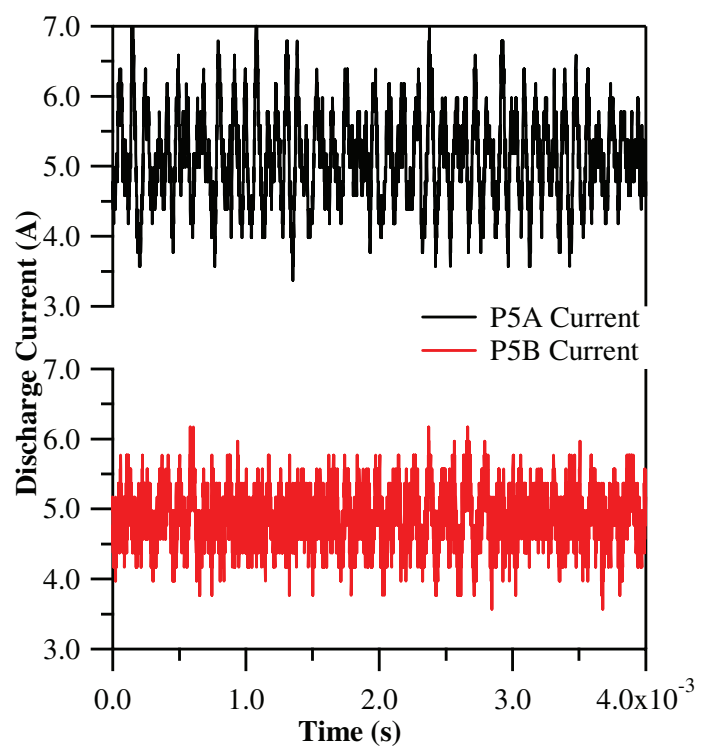

Fig. 5 Cluster discharge current with the P5-A operating at $300 \mathrm{~V}$, 5.14 $\mathrm{A}$ and the P5-B operating at $300 \mathrm{~V}, 4.96 \mathrm{~A}$. The measurements are taken at a nominal pumping speed of $240 \mathrm{kl} / \mathrm{s}$ : $7.2 \times 10^{-4} \mathrm{~Pa}$ $\left(5.4 \times 10^{-6}\right.$ Torr $)$.

\section{Discussion}

The following discussion compares the results of two techniques to correct the measured thrust for facility backpressure. Several factors control how the facility backpressure affects thruster operation. These include the random flux, the "effective area" into which the flux goes, and the "influence coefficient" of the random flux. The random flux is not represented by measurements at the chamber wall, either pressure or temperature, but rather is a local phenomenon dictated by conditions in the vicinity of the thruster. The "influence coefficient" is clearly controlled by both thruster design and operating condition, the former via the standard open area of the channel, magnetic field profile, and cathode fall voltage, and the latter by the distribution of the Hall current, the cathode fall voltage, and plume fields. Obviously, the random flux itself is also influenced by the thruster (or cluster) as it will control the local density and temperature that result in the random flux. Thus, a very simple random flux correction technique cannot capture all of the detail of the ingestion process. The complexity of these physics leads to the "current increment" technique, which provides a way to access both the effective area and the influence coefficient via a direct measurement.

\section{Monolithic}

Figures 6 and 7 present the anode efficiency and anode specific impulse of the P5-A, respectively. Because the performance parameters of the P5-A and P5-B are similar, only the anode efficiency of the P5-A is shown. Figure 6 shows that, in general, for a given flow rate the anode efficiency increases with discharge voltage until a maximum is reached. Any further increase in voltage has little effect on the efficiency or causes it to decrease. Increasing the anode mass flow rate from 5.25 to $10.46 \mathrm{mg} / \mathrm{s}$ increases the maximum efficiency. At an anode flow rate of $5.25 \mathrm{mg} / \mathrm{s}$ with a backpressure of $1.2 \times 10^{-3} \mathrm{~Pa}-\mathrm{Xe}\left(9.1 \times 10^{-6}\right.$ Torr-Xe), the anode efficiency decreases with increasing discharge voltage. At this condition the ingested flow rate, calculated as previously described, is $0.8 \%$ of the injected anode flow, the highest ratio of injected flow to ingested flow. It appears that the increase in discharge current caused by background gas ingestion overwhelms the commensurate increase in thrust. Therefore, more power is supplied to the thruster, but the beam jet power does not increase as quickly. We believe this trend is caused by poor thruster operation at $5.25 \mathrm{mg} / \mathrm{s}$. Unfortunately, the physical mechanisms that govern how the ingested particles interact with the ionization and acceleration process (which leads to the 


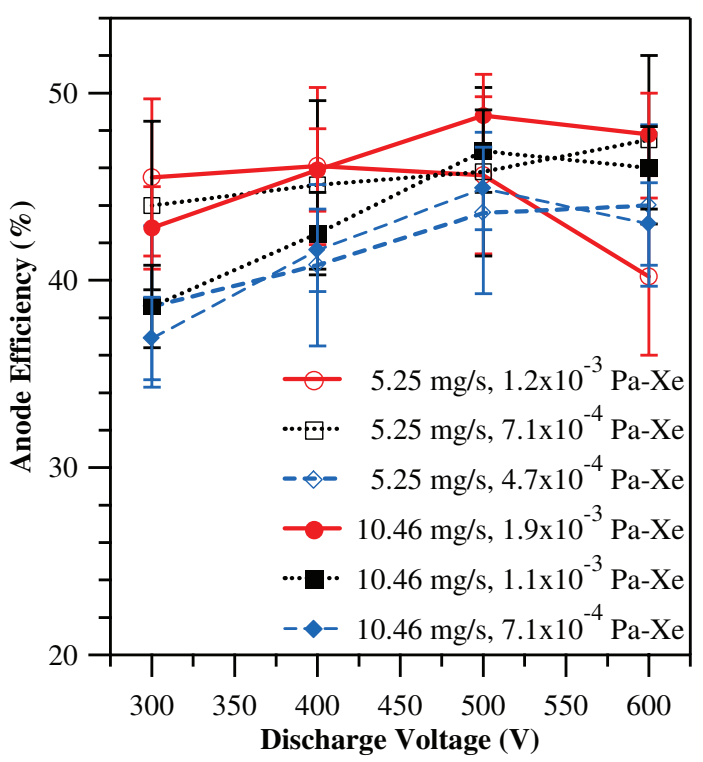

Fig. 6 The P5-A anode efficiency vs discharge voltage.

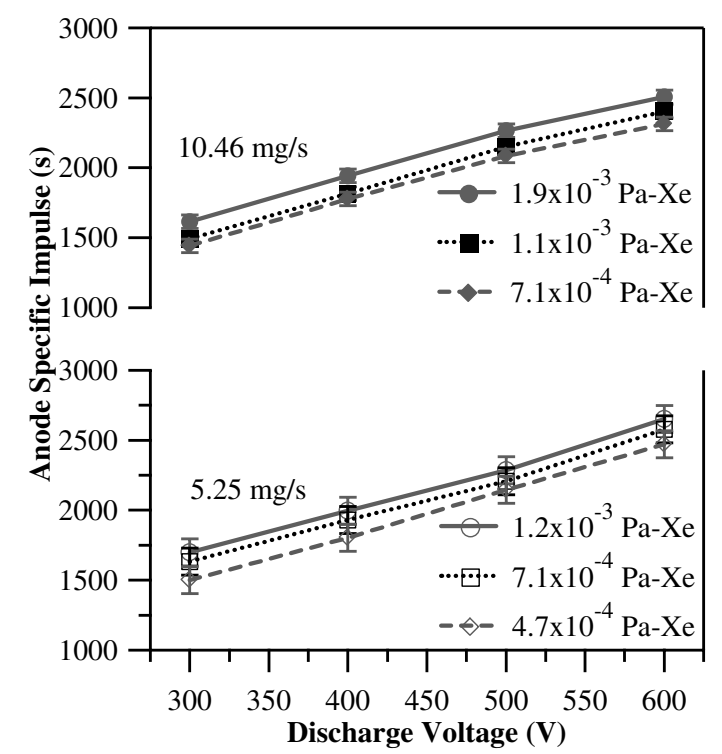

Fig. 7 The P5-A anode specific impulse vs discharge voltage.

decrease in anode efficiency) are not understood. Later in this section we will demonstrate two techniques to correct thrust measurements taken at elevated backpressures. Figure 7 presents the anode specific impulse for the P5-A. As expected, for each anode flow rate, the specific impulse increases continually with increasing discharge voltage [9].

As shown in Figs. 2 and 3 , the performance of a Hall thruster is affected by the facility backpressure. The random flux of neutral particles is ingested into the discharge channel. The ingested background gas increases the thrust, discharge current, and amplitude of the discharge current oscillations of the thruster for a given operating condition. The ingested background particles are ionized in or just downstream of the discharge channel and accelerated, artificially modifying the measured thrust. In addition, oscillations of the discharge current and electron collisions with the ingested neutrals enhance the electron mobility across the magnetic field. The increase in the number of electrons that reach the anode increases the discharge current. Several studies have attempted to explain the phenomena behind this behavior $[3,17]$. One approach that is routinely applied to correct performance data for ingested flow is to extrapolate mass flow rate versus pressure data to zero background pressure [18].
With the thrust data collected across the P5 Hall thruster operating range at three operating pressures and two anode flow rates we look to quantify the effects of the ingestion of neutral background gas at the Hall thruster exit plane. From this, we attempt to develop a tool to correct the performance of a Hall thruster operated at elevated facility backpressure. The first approach taken in this paper to correct the thrust measurement of a thruster operated at elevated backpressure is to account for the thrust increment that may be provided by the ingested gas that is accelerated downstream [19]. Equation (2) is used to calculate the random flux $\Phi$ of neutral particles into the discharge chamber, where $n_{b}$ is the background gas density, $T$ is the neutral particle temperature, and $m$ is the mass of one particle of background gas. We assume that the background gas has reached a thermal equilibrium temperature of $300 \mathrm{~K}$ with the chamber walls.

$$
\Phi=\frac{1}{4} n_{b}\left(\frac{8 k T}{\pi m}\right)^{1 / 2}
$$

Equation (3) shows the calculated mass flow rate $\dot{m}_{\text {en }}$ of ingested background gas into the chamber for an effective open area $A_{\text {eff }}$ of the discharge channel $\left(0.0118 \mathrm{~m}^{2}\right.$ for the P5) [2]. Note that if the discharge extends significantly past the exit plane of the thruster then the effective area of the discharge is incorrect.

$$
\dot{m}_{\mathrm{en}}=\Phi m A_{\mathrm{eff}}
$$

Next, assume that the Hall thruster has an ionization efficiency of $80 \%$ for neutral propellant that originates from the anode $[20,21]$. However, the ionization probability $P_{i}$ of an ingested particle is much higher because any particle that makes it through the ionization region on the way into the channel must travel through the ionization region a second time as it exits the channel. The ions are accelerated to a velocity $v_{i}$, which Gulczinski and Walker measured with an energy analyzer on the P5 Hall thruster $[\underline{22}, 23]$. The thrust increment created by ingested background neutrals, $F$ aug, is now calculated with Eq. (4) and used to correct the thrust measurements.

$$
F_{\text {aug }}=\dot{m}_{\mathrm{en}} v_{i} P_{i}
$$

The random flux calculation is based on the measured facility pressure and the chamber wall temperature.

Figure 8 shows the relative error between thrust measurements taken at $\overline{1} 40$ and $240 \mathrm{kl} / \mathrm{s}$ for anode flow rates of 5.25 and $10.46 \mathrm{mg} / \mathrm{s}$. The uncorrected curve uses the thrust measurement taken at the lower pressure as the true value and the thrust measurement at the higher pressure as the actual value to calculate the relative error. The uncorrected data show that the relative error between thrust measurements taken at a pumping speed of 140 and $240 \mathrm{kl} / \mathrm{s}$ is as much as $8 \%$. The corrected data show that the "random flux" correction method does not adequately account for the phenomena created by elevated backpressure.

As stated earlier, the ingestion area may be larger than the discharge channel open area. Analysis of the thrust data shows that the ingestion area needs be $2-14$ times the discharge channel open area to fully correct for the thrust increment with the random flux technique. It does not appear that the random flux technique captures the physical processes that account for the effects of elevated facility backpressure.

The second approach is to use the increment in discharge current between two pumping speeds to calculate the flux of neutral particles ingested into the anode. If we assume that the increment in discharge current is created by the single ionization of background particles ingested across the exit plane of the discharge channel we can calculate the ingested mass flow rate. The results of the "current increment" technique show that the particle flux into the discharge chamber is an order of magnitude greater than that calculated with the random flux using the facility backpressure near the wall and an assumed temperature of $300 \mathrm{~K}$ [12]. The augment in thrust is calculated with the same method used in the random flux technique. Figure 9 shows the relative error between the measured thrust and the corrected thrust using the current increment technique. Notice that the relative error of the $300 \mathrm{~V}, 5.25 \mathrm{mg} / \mathrm{s}$ condition at the 


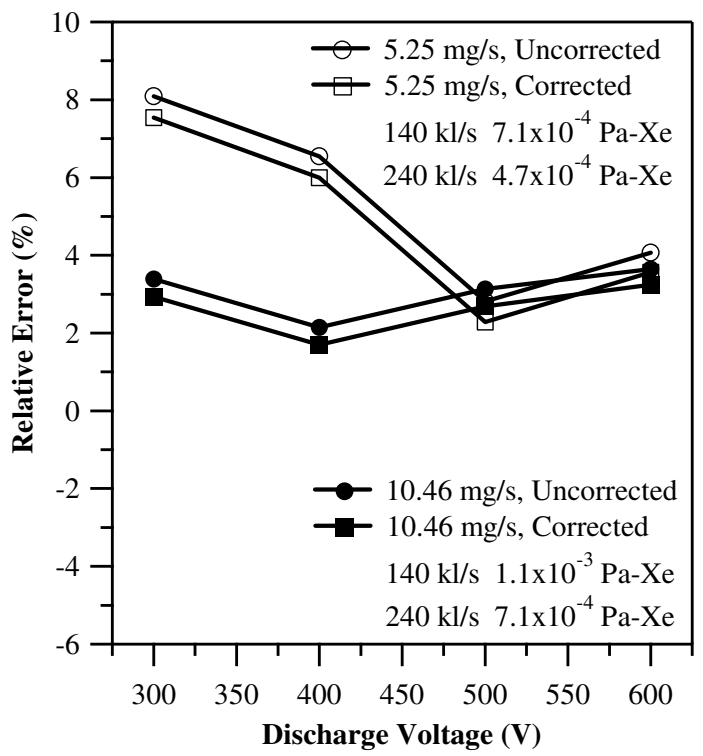

Fig. 8 Relative error in thrust for the P5-A at nominal pumping speeds of 140 and $240 \mathrm{kl} / \mathrm{s}$ for anode flow rates of 5.25 and $10.46 \mathrm{mg} / \mathrm{s}$ with the random flux technique.

$70-140 \mathrm{kl} / \mathrm{s}$ case is large. As stated earlier, we believe this is caused by poor operation of the thruster, which allows an abnormal number of electrons to reach the anode and not a result of the correction technique. The relative error in thrust with the current increment thrust correction technique is between $-4 \%$ and $+2 \%$ for the large majority of the operating conditions. Comparison of the relative errors shows that the current increment technique is superior to the random flux technique, which uses the measured facility pressure and the chamber wall temperature.

To further correct for the effect of ingested background gas on the performance of a Hall thruster fully, the composition of the plume must be characterized at each backpressure pressure. As the backpressure increases, a greater number of multiply charged ions may be created in the discharge chamber [24]. The percentage of multiply charged ions must be quantified to correct the thrust because the exit velocity of each ion depends on the ion charge state. Measurements in the plume of the P5 show the location and percentage of multiply charged species, but the origin of the neutral particles is not clear $[\underline{22}, \underline{23}]$.

\section{Cluster}

To use a cluster of Hall thrusters to create a high-power electric propulsion system, it is imperative to understand how the thrust of each engine contributes to that of the cluster. The following section compares the performance of the monolithic thruster to that of the cluster. The effect of facility backpressure is also included in the comparison.

Figures 10 and 11 compare the addition of the thrust of the P5-A and P5-B to the $T_{C}$. All of the cluster thrust measurements are greater than the addition of the two monolithic thrusters beyond the error of the thrust stand. One reason for this result is that the cluster introduces twice the mass flow rate of propellant into the facility, nearly doubling the backpressure in comparison to the same operating condition for a single thruster. Therefore, the thrust augmentation due to ingestion is greater for each element of the cluster than for the monolithic test case. The measurements of the $T_{C}$ will be compared to the addition of the monolithic thrust measurements at equivalent pressures later in this article. In addition, the cluster shows a much larger enhancement in thrust with increasing facility backpressure than was seen with the monolithic thruster. Plume interaction may also enhance the $T_{C}$. Beal found that the electric field in the plume of an adjacent thruster turns divergent beam ions axially [25]. This focusing of ions leads to a decrease in the plume divergence angle and thus an increase in thrust.

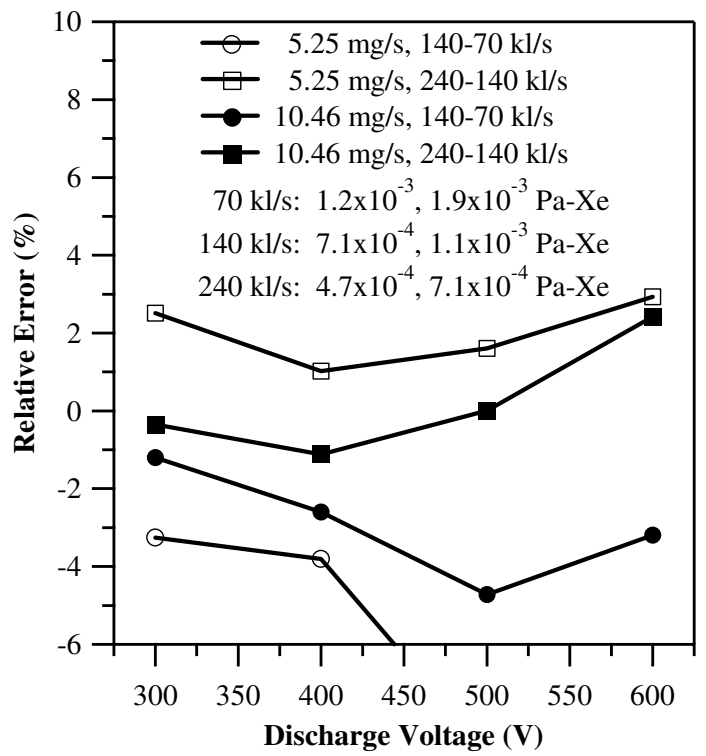

Fig. 9 Relative error in corrected thrust for the P5-A at nominal pumping speeds of 70, 140, and $240 \mathrm{kl} / \mathrm{s}$ for anode flow rates of 5.25 and $10.46 \mathrm{mg} / \mathrm{s}$ with the current increment technique.

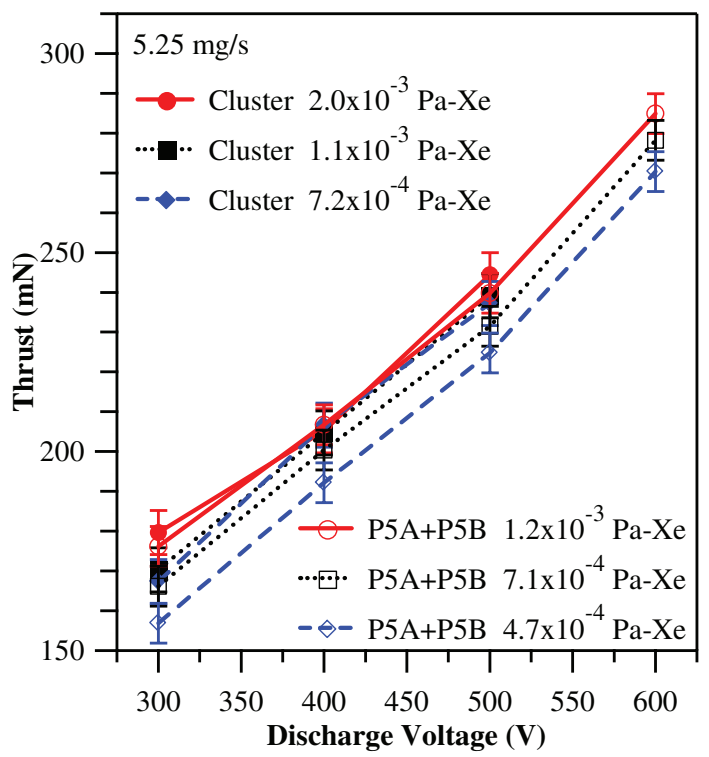

Fig. 10 Cluster thrust measurements in comparison to the addition of the monolithic thrust for an anode flow rate of $5.25 \mathrm{mg} / \mathrm{s}$ at nominal pumping speeds of 70, 140, and $240 \mathrm{kl} / \mathrm{s}$.

Figure 12 shows the thrust percentage difference between the measured $T_{C}$ and the sum of $T_{\mathrm{P} 5-\mathrm{A}}$ and $T_{\mathrm{P} 5 \text { - }}$ for flow rates of 5.25 and $10.46 \mathrm{mg} / \mathrm{s}$ at the three pumping speeds. The thrust percent difference is calculated as follows:

$$
\left[T_{C}-\left(T_{\mathrm{P} 5-\mathrm{A}}+T_{\mathrm{P} 5-\mathrm{B}}\right)\right] /\left(T_{\mathrm{P} 5-\mathrm{A}}+T_{\mathrm{P} 5-\mathrm{B}}\right)
$$

There is not a large change in the thrust percent difference as the discharge voltage increases. The percent difference in thrust for the $10.46 \mathrm{mg} / \mathrm{s}$ anode flow rate varies from 11 to $16 \%$, where the monolithic and cluster operating pressure varies over the range presented in Table 1 . The $10.46 \mathrm{mg} / \mathrm{s}$ data yield greater percent differences in thrust than data for the $5.25 \mathrm{mg} / \mathrm{s}$ anode flow rate cases, which vary from 0 to $6 \%$. These differences exist because the facility backpressure is greatest at the $10.46 \mathrm{mg} / \mathrm{s}$ anode flow rate; thus the thrust augmentation due to ingestion is greatest. For a given flow rate, the thrust percent difference increases as the operating pressure decreases. This is primarily because $T_{\mathrm{P} 5-\mathrm{A}}$ or $T_{\mathrm{P} 5-\mathrm{B}}$, 


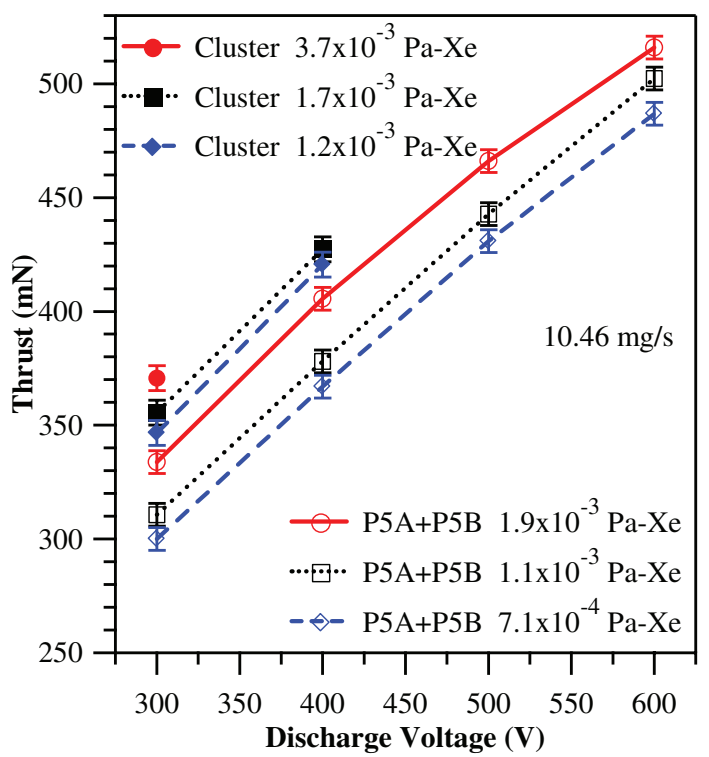

Fig. 11 Cluster thrust measurements in comparison to the addition of the monolithic thrust at an anode flow rate of $10.46 \mathrm{mg} / \mathrm{s}$ at nominal pumping speeds of 70,140 , and $240 \mathrm{kl} / \mathrm{s}$.

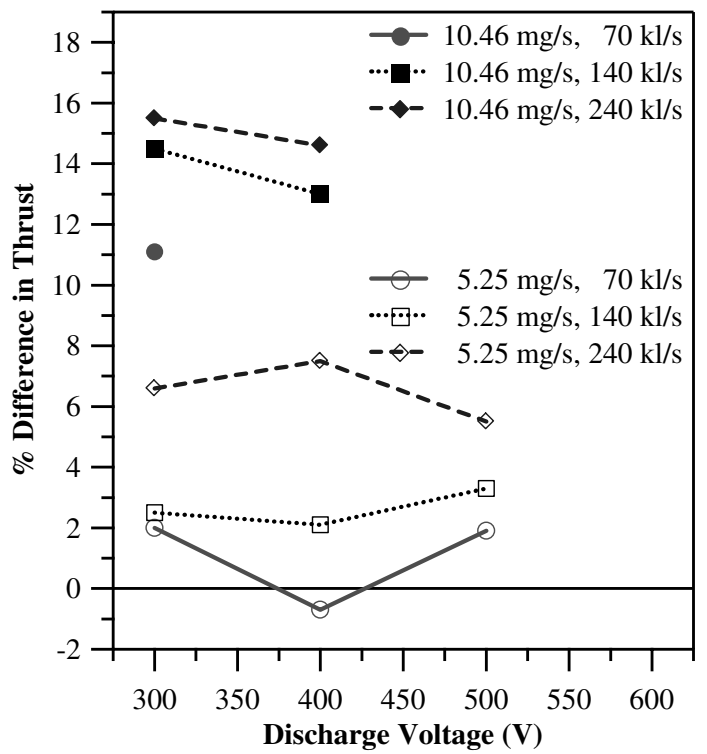

Fig. 12 Percent difference between measured cluster thrust and the addition of the measured monolithic thrust at anode flow rates of $\mathbf{5 . 2 5}$ and $10.46 \mathrm{mg} / \mathrm{s}$ at nominal pumping speeds of 70,140 , and $240 \mathrm{kl} / \mathrm{s}$.

measured when either thruster is operated alone, decreases with backpressure faster than $T_{C}$ decreases with pressure.

Figure 13 shows a plot of cluster anode efficiency as a function of voltage. In general, the cluster anode efficiency increases with discharge voltage for a given anode flow rate. However, at an anode flow rate of $5.25 \mathrm{mg} / \mathrm{s}$ with an operating pressure of $2.0 \times$ $10^{-3} \mathrm{~Pa}-\mathrm{Xe}\left(1.5 \times 10^{-5}\right.$ Torr-Xe $)$, the cluster anode efficiency decreases with increasing discharge voltage. The same behavior is seen in Fig. 6 for the P5-A. The ingested flow rate, calculated with kinetic theory, is only $1.3 \%$ of the injected anode flow at this condition. This condition has the highest ratio of injected flow to ingested flow of the cluster measurements. As is shown with the monolithic thruster, the increase in discharge current overwhelms the increase in thrust. Thus, the ratio of supplied power to beam jet power decreases, which results in the decrease in anode efficiency as discharge voltage of the cluster increases. The cluster anode efficiency is greatest at the $10.46 \mathrm{mg} / \mathrm{s}$ anode flow rate, which is the same behavior seen in the monolithic anode efficiency. The anode efficiency increases with facility backpressure because the

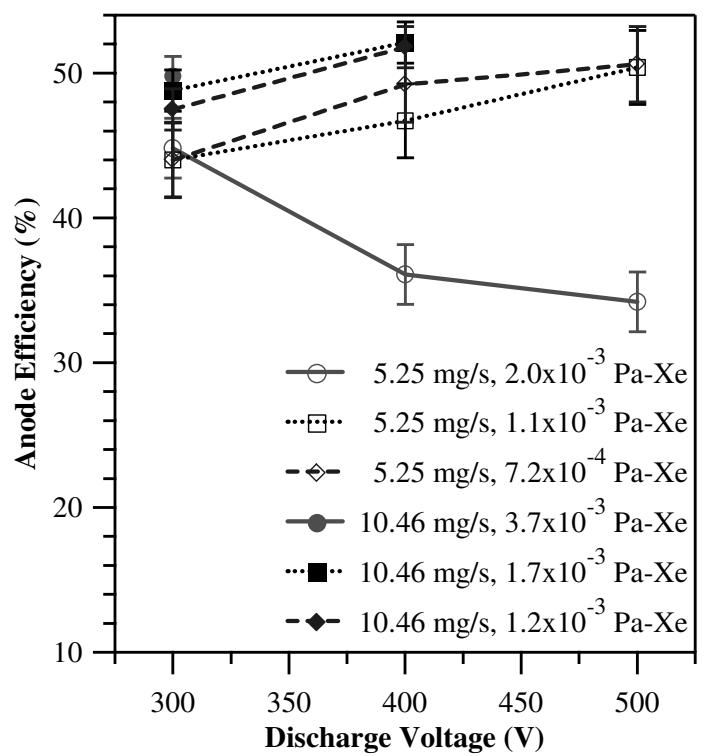

Fig. 13 Cluster anode efficiency vs discharge voltage at nominal pumping speeds of 70,140 , and $240 \mathrm{kl} / \mathrm{s}$.

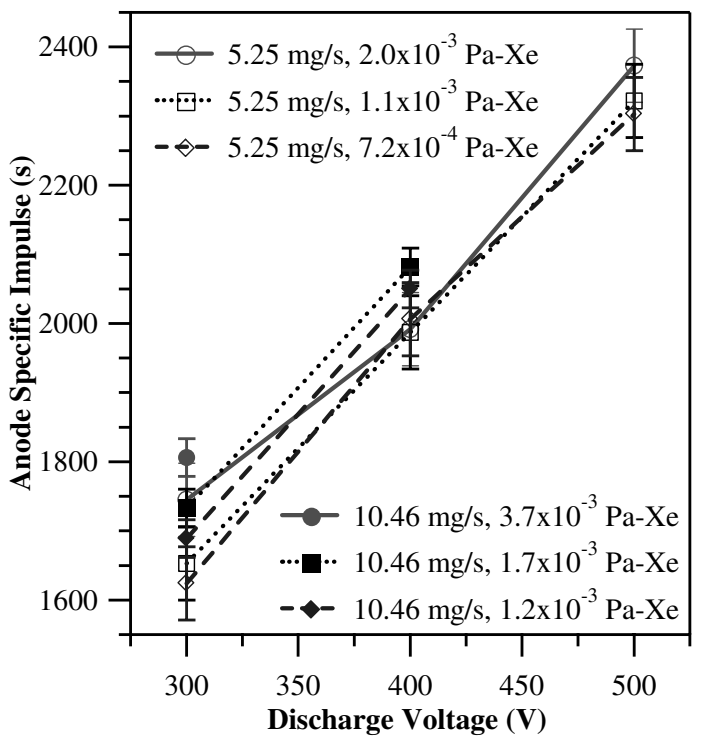

Fig. 14 Cluster anode specific impulse vs discharge voltage at nominal pumping speeds of 70, 140, and $240 \mathrm{kl} / \mathrm{s}$.

background gas ingestion artificially increases the thrust at a rate that is greater than the increase in power supplied to the thruster. This trend is also apparent in the monolithic thruster efficiency.

Figure 14 shows the cluster specific impulse. The cluster specific impulse increases continually as the discharge voltage increases. The same trend is observed in the specific impulse of the monolithic thrusters. The cluster specific impulse appears to increase slightly with anode flow rate for the measured points. This trend is opposite of the one seen with the monolithic thrusters. The specific impulse is a function of the exit velocity of the particles, which is determined by the discharge voltage. The analysis shows that the cluster specific impulse appears to increase as the facility backpressure increases for a constant discharge voltage because whereas the ingested background gas increases the thrust, the ingested flow is not accounted for in the calculation of the anode specific impulse.

Performance of monolithic and clustered thrusters at the same operating condition and backpressure are shown in Figs. 15-17. As indicated in each figure, the operating pressure of the monolithic thruster and the cluster is approximately the same for anode flow rates of 5.25 and $10.46 \mathrm{mg} / \mathrm{s}$. Figure 15 shows that at the $5.25 \mathrm{mg} / \mathrm{s}$ 


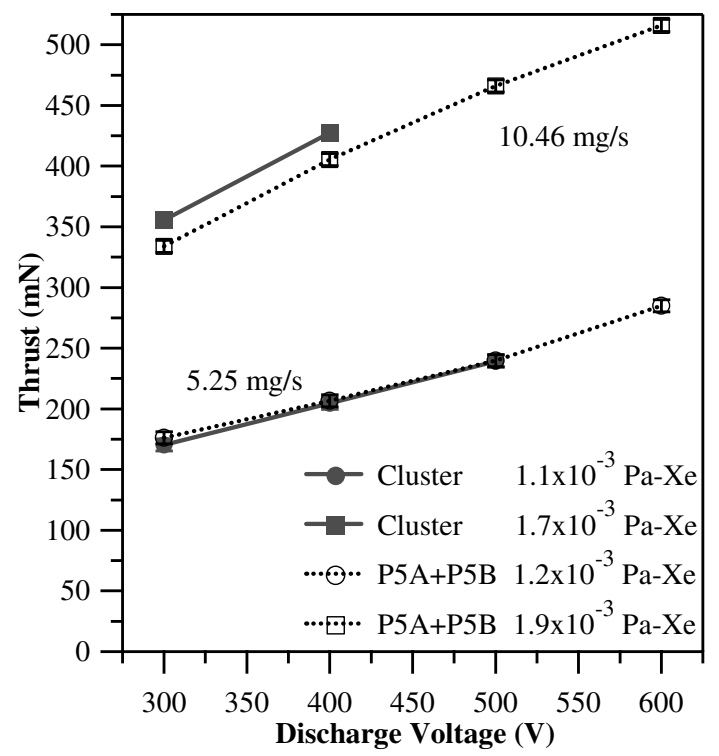

Fig. 15 Thrust vs discharge voltage for the sum of the P5-A and P5-B at a nominal pumping speed of $70 \mathrm{kl} / \mathrm{s}$, and the thrust of the cluster at nominal pumping speed of $140 \mathrm{kl} / \mathrm{s}$.

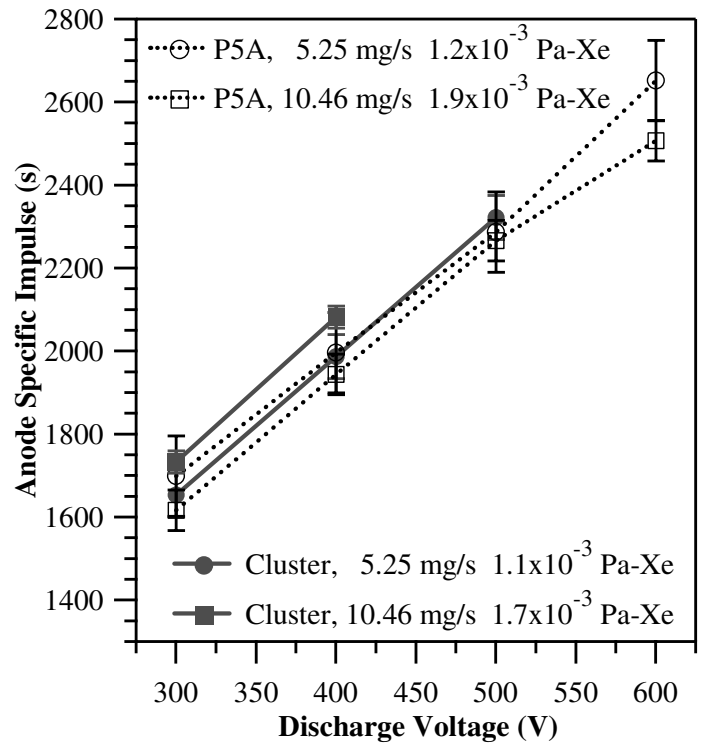

Fig. 16 Specific impulse vs discharge voltage for the sum of the P5-A at a nominal pumping speed of $70 \mathrm{kl} / \mathrm{s}$ and the cluster at a nominal pumping speed of $140 \mathrm{kl} / \mathrm{s}$.

flow rate, the sum of $T_{\mathrm{P} 5-\mathrm{A}}$ and $T_{\mathrm{P} 5-\mathrm{B}}$ is approximately equal to $T_{C}$. However, at the $10.46 \mathrm{mg} / \mathrm{s}$ flow rate $T_{C}$ is greater the sum of $T_{\mathrm{P} 5-\mathrm{A}}$ and $T_{\mathrm{P} 5-\mathrm{B}}$. The fact that $T_{C}$ is greater than the sum of $T_{\mathrm{P} 5-\mathrm{A}}$ and $T_{\mathrm{P} 5-\mathrm{B}}$ may be caused by each cluster element elevating the operating pressure in the immediate vicinity of the adjacent thruster. The elevated operating pressure also affects the cluster and anode efficiency at the $10.46 \mathrm{mg} / \mathrm{s}$ anode flow rate.

Figure 16 shows that at the $5.25 \mathrm{mg} / \mathrm{s}$ anode flow rate the specific impulse of the cluster is approximately the same as that of the monolithic thruster. However, at the $10.46 \mathrm{mg} / \mathrm{s}$ flow rate, the specific impulse of the cluster is approximately $250 \mathrm{~s}$ greater than that of the monolithic thruster. As discussed earlier, the increase in cluster specific impulse is caused by not accounting for the ingested background gas in the calculation of specific impulse.

Figure 17 shows that at the $5.25 \mathrm{mg} / \mathrm{s}$ anode flow rate, the anode efficiency of the cluster is approximately the same as that of the monolithic thruster, within the error of the measurement. At the $10.46 \mathrm{mg} / \mathrm{s}$ anode flow rate, the cluster anode efficiency is higher than the anode efficiency of the monolithic thruster.

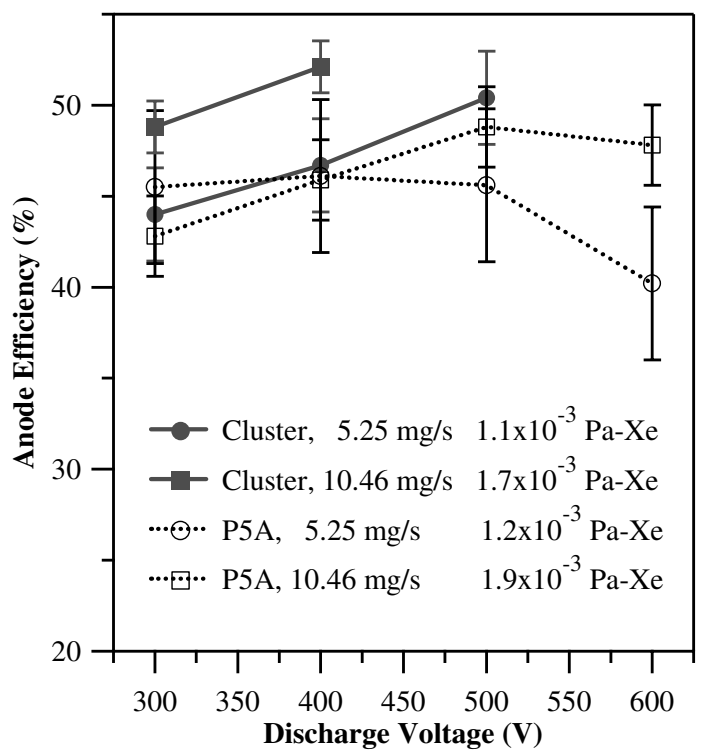

Fig. 17 Anode efficiency vs discharge voltage for the sum of the P5-A at a nominal pumping speed of $70 \mathrm{kl} / \mathrm{s}$, and the cluster at a nominal pumping speed of $140 \mathrm{kl} / \mathrm{s}$.

\section{Conclusions}

An improved backpressure correction technique based on incremental current change was demonstrated to predict thrust changes within $-4 \%$ to $+2 \%$, significantly better than a simple random flux calculation that uses the measured facility pressure and chamber wall temperature. It may also be possible to move the elements of the cluster closer together without adversely affecting their performance.

Analysis of the measurements of the thrust of P5-A, $T_{\mathrm{P} 5-\mathrm{A}}$, and the thrust of $\mathrm{P} 5-\mathrm{B}, T_{\mathrm{P} 5-\mathrm{B}}$, shows that as the facility backpressure increases, the thruster discharge current and thrust increase as more background xenon gas is ingested into the thruster discharge chamber, as is expected. The percent difference between the measured thrust of the cluster, $T_{C}$, and the sum of $T_{\mathrm{P} 5 \text {-A }}$ and $T_{\mathrm{P} 5 \text {-B }}$ for the $10.46 \mathrm{mg} / \mathrm{s}$ anode flow rate varies from 11 to $16 \%$ over the range of operating pressures investigated. This is greater than the percent difference in thrust for the $5.25 \mathrm{mg} / \mathrm{s}$ anode flow rate, which varies from 0 to $6 \%$ over the range of operating pressures. The difference between the two flow rates is caused by the ingestion of background gas and thus, the difference between $T_{C}$ and the addition of $T_{\mathrm{P} 5-\mathrm{A}}$ and $T_{\mathrm{P} 5-\mathrm{B}}$ increases as the operating pressure decreases. The efficiency values of the cluster are slightly greater than those of the monolithic thruster. The difference appears to be caused by the ingested background gas. The specific impulse of the cluster increases with discharge voltage. However, the specific impulse increases with facility backpressure, which was not seen with the monolithic thruster. This is possibly due to the fact that the calculation of specific impulse does not take the ingested background gas into account.

Comparison of the performance characteristics of the cluster and the monolithic thruster at conditions of nearly equal operating pressure shows that for the $5.25 \mathrm{mg} / \mathrm{s}$ anode flow rate $T_{C}$ is simply the addition of $T_{\mathrm{P} 5-\mathrm{A}}$ and $T_{\mathrm{P} 5-\mathrm{B}}$. In addition, the anode efficiency and specific impulse are approximately equal to that of the monolithic thruster. However, these trends do not hold at the $10.46 \mathrm{mg} / \mathrm{s}$ anode flow rate for conditions of equal operating pressure because each cluster element elevates the operating pressure in the immediate vicinity of the adjacent thruster and the effects of ingestion are apparent.

\section{Acknowledgments}

The research contained herein was sponsored by the Air Force Office of Scientific Research. (Mitet Birkan is the contract monitor.) M. L. R. Walker is supported by the Michigan Space Grant 
Consortium and the National Science Foundation. We would like to thank James Haas at AFRL for supplying the Plasmadynamics and Electric Propulsion Laboratory (PEPL) with the cluster elements, Terry Larrow for fabricating the hardware used in this study, Sergi Khartov at the Moscow Aviation Institute for use of the $\mathrm{LaB}_{6}$ cathode design, and the departmental technical staff and other graduate students at PEPL for help in maintaining the facilities. We would also like to thank Torsten Stindl of the University of Stuttgart. The authors are greatly appreciative of this support.

\section{References}

[1] Spores, R. A., Spanjers, G. G., Birkan, M., and Lawrence, T. J., "Overview of the USAF Electric Propulsion Program," AIAA Paper 2001-3225, July 2001.

[2] Randolph, T., Kim, V., Kaufman, H., Kozubsky, K., Zhurin, V. V., and Day, M., "Facility Effects on Stationary Plasma Thruster Testing," IEPC Paper 93-093, Sept. 1993.

[3] Semenkin, A., Kim, V., Gorshkov, O., and Jankovsky, R. S., "Development of Electric Propulsion Standards-Current Status and Further Activity," IEPC Paper 2001-070, Oct. 2001.

[4] King, L. B., and Gallimore, A. D., "Ionic and Neutral Particle Transport Property Measurements in the Plume of an SPT-100," AIAA Paper 962712, July 1996.

[5] Beal, B. E., and Gallimore, A. D., "The Effects of Clustering Multiple Hall Thrusters on Plasma Plume Properties," AIAA Paper 2003-5155, July 2003.

[6] Beal, B. E., Gallimore, A. D., and Hargus, W., Jr., "Preliminary Plume Characterization of a Low-Power Hall Thruster Cluster," AIAA Paper 2002-4251, July 2002.

[7] Beal, B. E., and Gallimore, A. D., "Energy Analysis of a Hall Thruster Cluster," IEPC Paper 03-0035, March 2003.

[8] Hargus, W. A., Jr., and Reed, G., "The Air Force Clustered Hall Thruster Program," AIAA Paper 2002-3678, July 2002.

[9] Haas, J. M., Gulczinski, F. S., III, Gallimore, A. D., Spanjers, G. G., and Spores, R. A., "Performance Characteristics of a $5 \mathrm{~kW}$ Laboratory Hall Thruster," AIAA Paper 98-3503, July 1998.

[10] Walker, M. L. R., and Gallimore, A. D., "Performance Characteristics of a Cluster of $5 \mathrm{~kW}$ Laboratory Hall Thrusters," AIAA Paper 20043767, July 2004.

[11] Peterson, P. Y., Gallimore, A. D., and Haas, J. M., "An Experimental Investigation of the Internal Magnetic Field Topography of an Operating Hall Thruster," Physics of Plasmas, Vol. 9, No. 10, Oct. 2002, pp. 4354-4362.

[12] Walker, M. L. R., and Gallimore, A. D., "Neutral Density Map of Hall
Thruster Plume Expansion in a Vacuum Chamber," Review of Scientific Instruments, Vol. 76, No. 5, May 2005, p. 8.

[13] Walker, M. L. R., Gallimore, A. D., and Cai, C., , "Pressure Map of a Facility as a Function of Flow Rate to Study Facility Effects," AIAA Paper 2002-3815, July 2002.

[14] Dushman, S., Scientific Foundations of Vacuum Technique, Wiley, New York, 1958.

[15] Jankovsky, R. S., Jacobson, D., and Manzella, D. H., "50 kW Class Krypton Hall Thruster Performance," AIAA Paper 2003-4550, July 2003.

[16] Hofer, R. R., and Gallimore, A. D., "Recent Results from Internal and Very-Near-Field Plasma Diagnostics of a High Specific Impulse Hall Thruster," IEPC Paper 2003-037, March 2003.

[17] Hofer, R. R., Peterson, P. Y., and Gallimore, A. D., "Characterizing Vacuum Facility Backpressure Effects on the Performance of a Hall Thruster," IEPC Paper 01-045, Oct. 2001.

[18] de Grys, K. H., Meckel, N., Callis, G., Greisen, D., Hoskins, A., King, D., Wilson, F., Werthman, L., and Khayms, V., "Development and Testing of a 4500 Watt Flight Type Hall Thruster and Cathode," IEPC Paper 01-011, Oct. 2001.

[19] Manzella, D. H., and Sankovic, J. M., "Hall Thruster Ion Beam Characterization," AIAA Paper 95-2927, July 1995.

[20] Hofer, R. R., and Jankovsky, R. S., "A Hall Thruster Performance Model Incorporating the Effects of a Multiply-Charged Plasma," AIAA Paper 2001-3322, July 2001.

[21] Zhurin, V. V., Kaufman, H. R., and Robinson, R. S., "Physics of Closed Drift Thrusters," Plasma Sources Science and Technology, Vol. 8, No. 1, Feb. 1999, pp. R1-R20.

[22] Gulczinski, F. S., "Examination of the Structure and Evolution of Ion Energy Properties of a $5 \mathrm{~kW}$ Class Laboratory Hall Effect Thruster at Various Operational Conditions," Ph.D. Thesis, Univ. of Michigan, Dept. of Aerospace Engineering Microfilms International, Ann Arbor, MI, 1999.

[23] Walker, M. L. R., "Effects of Facility Backpressure on the Performance and Plume of a Hall Thruster," Ph.D. Thesis, Univ. of Michigan, Dept. of Aerospace Engineering Microfilms International, Ann Arbor, MI, 2005.

[24] Zhurin, V. V., Kahn, J., Kaufman, H., Kozubsky, K., and Day, M., "Dynamic Characteristics of Closed Drift Thrusters," IEPC Paper 93095, Sept. 1993.

[25] de Grys, K. H., Tilley, D. L., and Aadland, R. S., "BPT Hall Thruster Plume Characteristics," AIAA Paper 99-2293, June 1999.

R. Myers

Associate Editor 